\title{
POWER INVERTERS IN FORM OF MICROMODULE WITH DIRECT LIQUID COOLING
}

\author{
Alexander Krainyukov ${ }^{1}$, Rodions Saltanovs ${ }^{2}$ \\ ${ }^{1}$ SIA “ElGoo Tech”, Latvia; ${ }^{2}$ Riga Technical University, Latvia \\ krainukovs.a@tsi.lv
}

\begin{abstract}
The paper is devoted to determination of the efficiency of hybrid micro modules of power inverters with a switching frequency in the range from 0.1 to $0.3 \mathrm{MHz}$. To carry out the research $\mathrm{SiC}$ transistors C3M0065090J and eGaN EPC2035 transistors have been chosen, as these transistors have small cases and good frequency properties. Hybrid micro modules of power inverters were created on the basis of selected transistors using a welding device of one-sided contact micro welding. The test bench makes it possible to investigate the hybrid power micro modules under various operating conditions and cooling methods. The module efficiency research results are presented, when direct liquid cooling by silicone oil was used and the switching frequency was changed. It is established that the efficiency of the hybrid power micro modules exceeds 0.9 , even when the switching frequency equals $300 \mathrm{kHz}$, if eGaN transistors EPC2035 are used in the module.
\end{abstract}

Keywords: hybrid micro module, power inverter, liquid cooling, power transistor.

\section{Introduction}

Currently, power electronic inverters are widely used in devices and systems of various fields of science and technology, such as solar power, hybrid cars, electric vehicles, unmanned aerial vehicles, wind power, etc. Simultaneously, high demands are made on the energy, frequency, thermal, overall price and reliability characteristics of power electronic inverters [1-3].

Characteristics of power electronic inverters are determined mainly by the characteristics of power semiconductor devices used to create the inverters. Since the beginning of the eighties of the last century, silicon MOSFETs have been the main electronic components for creating power electronics devices and systems. At the beginning of this century silicon power technology had reached its limit, and silicon power MOSFETs did not meet the growing demands for reduced power consumption and reduced electronic power equipment [4].

Over the past 20 years, field effect transistors based on silicon carbide (SIC) and gallium nitride $(\mathrm{GaN})$ have been developed. At present, $\mathrm{SiC}$ [5] and $\mathrm{GaN}$ [6] are preferred for the creation of semiconductor devices for power electronics, since $\mathrm{SiC}$ and $\mathrm{GaN}$ significantly exceed $\mathrm{Si}$ and GaAs in their physical parameters. Transistors based on SIC and GaN have certain advantages over silicon MOSFETs: less mass, smaller dimensions, greater efficiency, greater operating frequency and improved reliability, simplicity of circuit implementation, as well as reduction in the complexity and cost of cooling systems.

High-frequency properties of SiC MOSFETs and GaN - the transistors determine the main trend in the development of power electronic inverters, which consists in increasing the switching frequency of inverters. Small size of SiC MOSFETs and GaN transistors corresponds to this trend, as it allows to use a modular approach for the development of power electronic inverters. The modular approach allows to reduce the parasitic reactivity of the inverter circuits, thereby increasing the switching frequency and improving the power characteristics of the electronic inverters. However, a reduction in the size of power inverters requires an increase in the efficiency of cooling systems for power micro modules. Analysis of the cooling technology of electronic power devices shows that the technology of direct liquid cooling (with immersing electronic devices) is more efficient, since it provides a greater drain of thermal energy from the surface of power electronic devices and components, especially for cooling electronic devices made by the modular technology [7-9].

However, liquid cooling technology requires the use of special dielectric liquids and devices ensuring the circulation of fluids. The relevance of our research has determined these trends in the development and use of power inverters based on SiC MOSFET and GaN-transistors.

The purpose of our research is to determine the efficiency of hybrid micromodules of power inverters based on SiC MOSFETs and GaN-transistors with a switching frequency in the range from 0.1 to $0.3 \mathrm{MHz}$, when direct liquid cooling is used for hybrid micro modules of power inverters. 


\section{Materials and methods}

\section{Hybrid micro modules of power inverters}

To carry out our research SIC MOSFETs of a new family - C3M0065090J [10] and eGaN transistors EPC2035 [11] were chosen to create hybrid micro modules of power inverters. The choice of these transistors is explained not only by their technical characteristics allowing implement power micro modules with the required parameters, but also by their cost characteristics and their availability with suppliers of electronic components.

$\mathrm{SiC}$ transistors C3M0065090J are the development of Cree Power, and they are silicon carbide silicon transistors of the third generation. The choice of C3M0065090J transistors is explained by the following factors:

- C3M0065090J transistors have parameters, which values are 3-4 times better than the corresponding parameters of the best power silicon MOSFEETs, for example: the open channel resistance is $65 \mathrm{~m} \Omega$; gate charge is $30 \mathrm{nCl}$; peak drain current is $90 \mathrm{~A}$; switching period $-16 \mathrm{~ns}$.

- C3M0065090J transistors are made in the D2PAK7 package (Fig. 1a), which has a rather large "leakage distance" $(7 \mathrm{~mm})$ between the source and drain. This makes it possible to reduce switching losses and to reduce oscillatory processes.

- C3M0065090J transistors allow to increase the operating frequency of power devices and to reduce the dimensions of transformers, accordingly, significantly to reduce heat generation, which makes it possible to reduce the dimensions of the used radiators.

- C3M0065090J transistors can be used instead of silicon IGBTs in voltage converters, inverters, power factor correctors, electric drives, welding equipment, induction heating, as well as in solar power and wind power.

a)

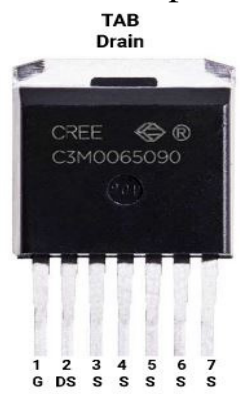

b)

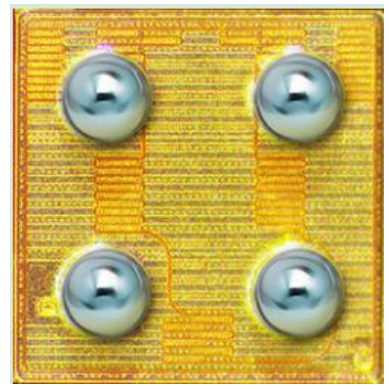

Fig. 1. Transistor case: $\mathrm{a}-\mathrm{SiC}$ transistor C3M0065090J; b - eGaN transistor EPC2035

eGaN EPC2035 transistors are the development of Efficient Power Conversion (EPC). The EPC2035 transistors are unique transistors of the eGaN series (Enhancement Mode Gallium Nitride Power Transistor Technology) and they in many respects outperform in a number of parameters the traditional power MOS-FET transistors. Features of eGaN-transistors EPC2035:

- eGaN-transistors EPC2035 have the following main parameters: the maximum drain-source voltage is $60 \mathrm{~V}$, open channel resistance is $45 \mathrm{~m} \Omega$; input capacitance $-115 \mathrm{pF}$; output capacitance is $90 \mathrm{pF}$; gate charge is $1.15 \mathrm{nC}$; nominal drain current at $25^{\circ} \mathrm{C}-1 \mathrm{~A}$; peak drain current is $24 \mathrm{~A}$; maximum gate voltage is $6 \mathrm{~V}$.

- eGaN transistor EPC2035 has a low thermal resistance of the crystal-case of the transistor $\left(6.5^{\circ} \mathrm{C} \cdot \mathrm{W}^{-1}\right)$ and is designed for operation in the operating temperature range from $-40{ }^{\circ} \mathrm{C}$ to $+150^{\circ} \mathrm{C}$.

- eGaN transistor EPC2035 is executed in the BGA- case (Fig.1.b) with the miniaturized sizes.

- eGaN transistors EPC2035 are used together with specialized drivers that are manufactured in the form of microcircuits, their sizes are several $\mathrm{mm}$, and the drivers are designed for operation in the temperature range of eGaN-transistors EPC2035.

The case features of the selected transistors determine the methods of their mounting on the printed circuit board. To mount the D2PAK7 case of the C3M0065090J transistor, it is necessary to use the surface mounting method on the board, connecting the pins of the D2PAK7 case with the 
printed conductors on the hybrid power module. The case of the EPC2035 transistor contains solder balls instead of the pins, which saves space on the board.

To create hybrid power micro modules, a one-sided contact micro-welding technology was chosen for mounting semiconductor devices and crystals to conductive elements of a printed circuit board. This mounting technology of electronic components was used because one-sided contact microwelding technology has the following advantages over other ways of obtaining micro-connections:

- possibility of obtaining welded joints of electronic components that do not allow for general heating;

- welded joints of large conductors to thin conductive films;

- wide range of welded materials.

Fig. 2.a shows the developed welding device of one-sided contact micro-welding. This device ensures the delivery of rectangular shaped pulses, regulated in amplitude and duration, onto welding electrodes, one of which contacts the welded conductor. The current flows through the "electrodeconductor-substrate-electrode" circuit, and the current causes local heating of the contacting surfaces, and this ensures joining of the welded materials. Figure 2.b shows hybrid micro modules of power inverters created on the basis of eGaN-transistors EPC2035 and SiC transistors C3M0065090J using a welding device of one-sided contact micro welding.

a)

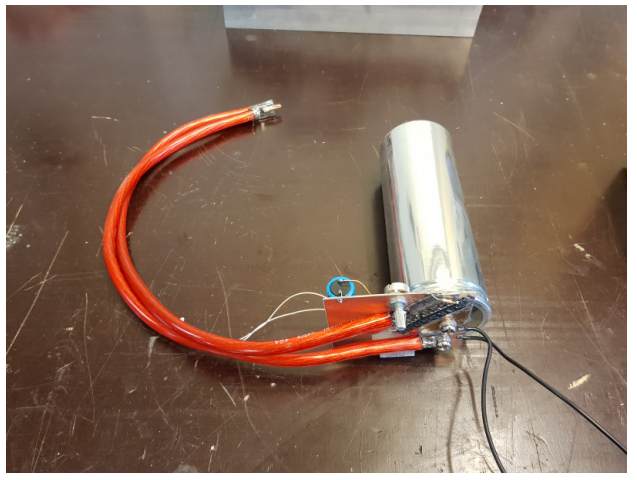

b)

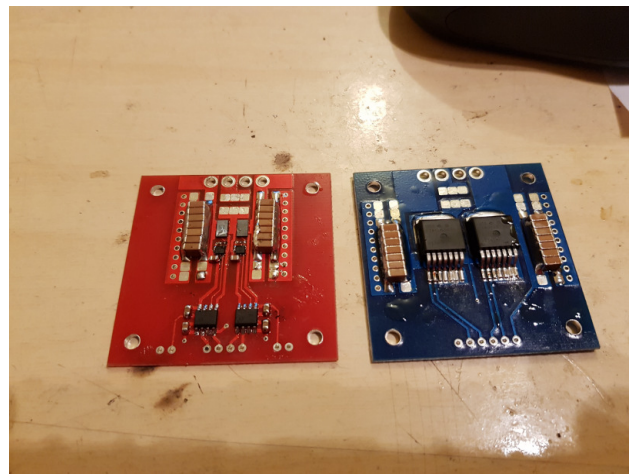

Fig. 2. General view of welding device of one-sided contact micro welding (a) and hybrid micro modules of power inverters (b) created on eGaN-transistors EPC2035 (on the left) and SiCtransistors C3M0065090J (on the right)

\section{The test bench for the research of the hybrid micro module parameters}

To research the efficiency of the functioning of the created hybrid micro modules of power inverters, the test bench was developed and created. The appearance of the test bench is shown in Figure 3. The test bench makes it possible to investigate the hybrid power micro modules under various operating conditions and cooling methods.

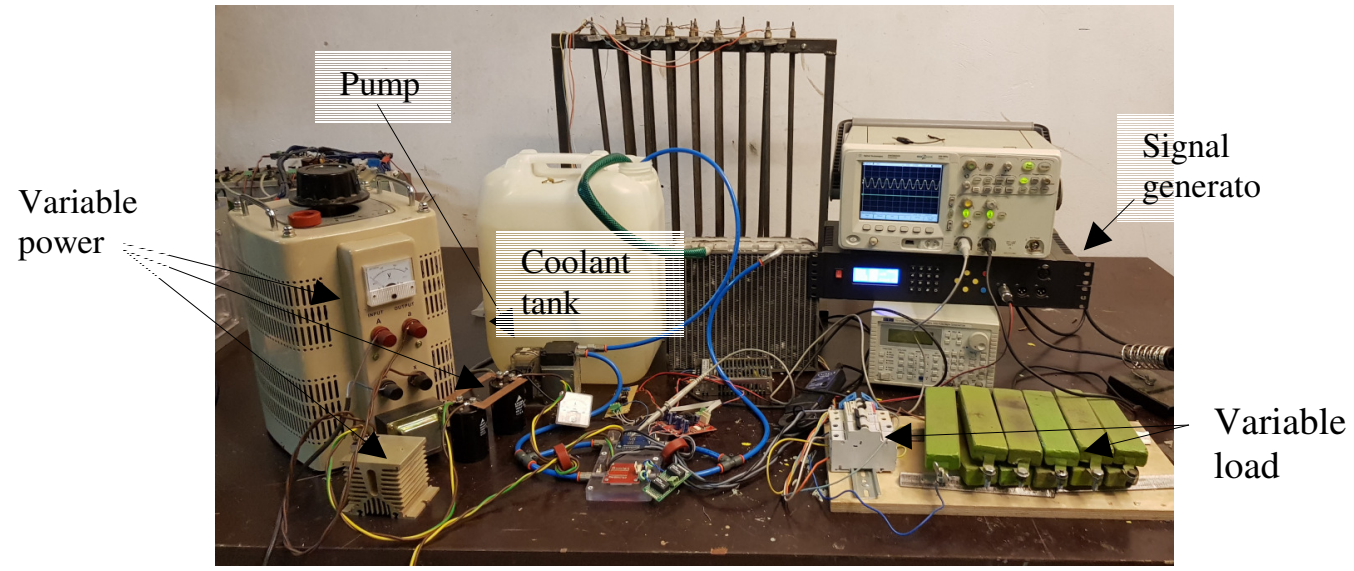

Fig. 3. Test bench for research of hybrid micro module parameters 
The test bench was developed on the basis of two structural schemes: electrical (Fig. 4) and hydraulic (Fig. 5).

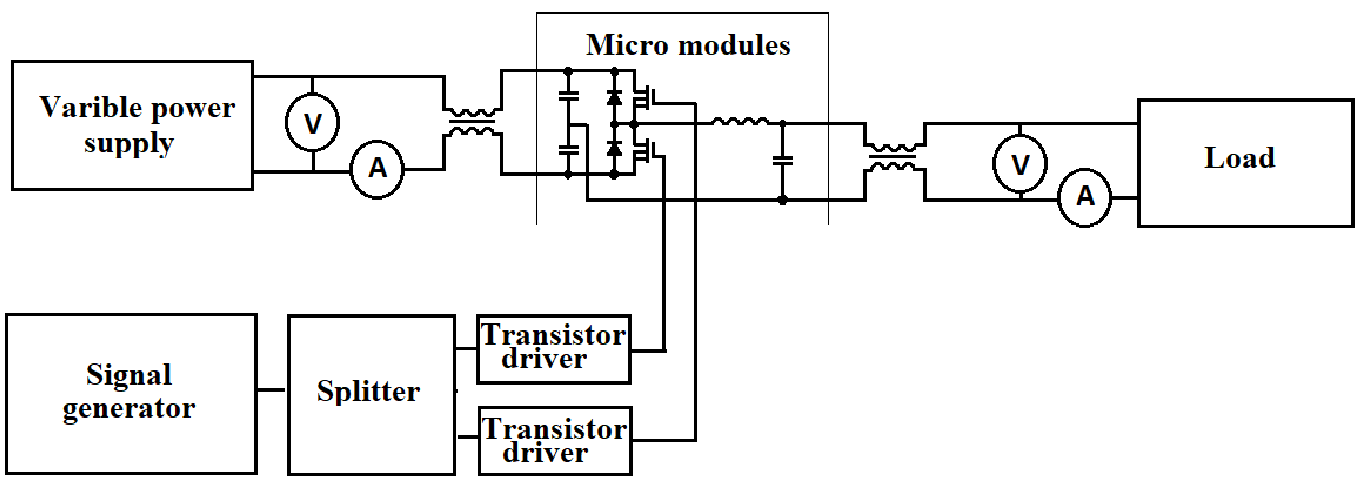

Fig. 4. Structural electrical scheme of test bench

The signal separator is designed to generate a meander signal from a sequence of input control rectangular pulses that are generated by the master oscillator. Transistor drivers provide the following functions: control of power inverter transistors in the hybrid micro modules, current protection of transistors, galvanic isolation on all control circuits.

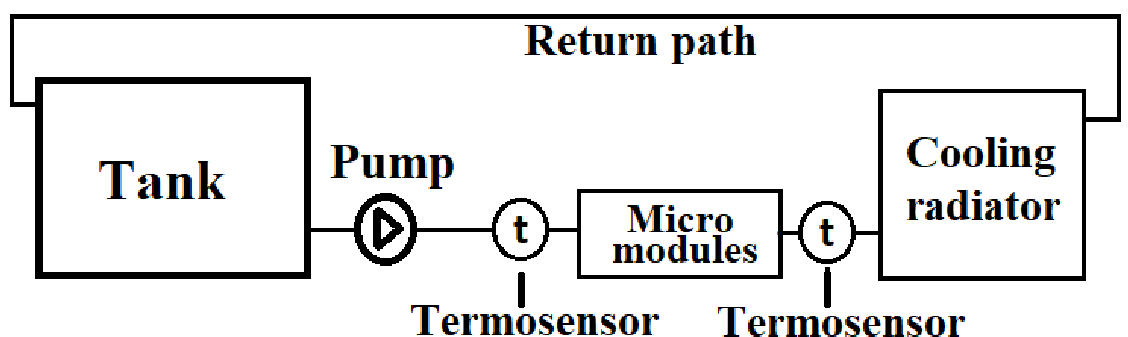

Fig. 5. Structural hydraulic scheme of test bench

To perform direct liquid cooling special cases were designed, in which the designed hybrid micro modules of power inverters were placed. Figure 6.a shows the hybrid micro modules of power inverters before they are inserted into the special cases. With direct liquid cooling the boards of the hybrid micro modules were in silicone oil $[12 ; 13]$.

a)

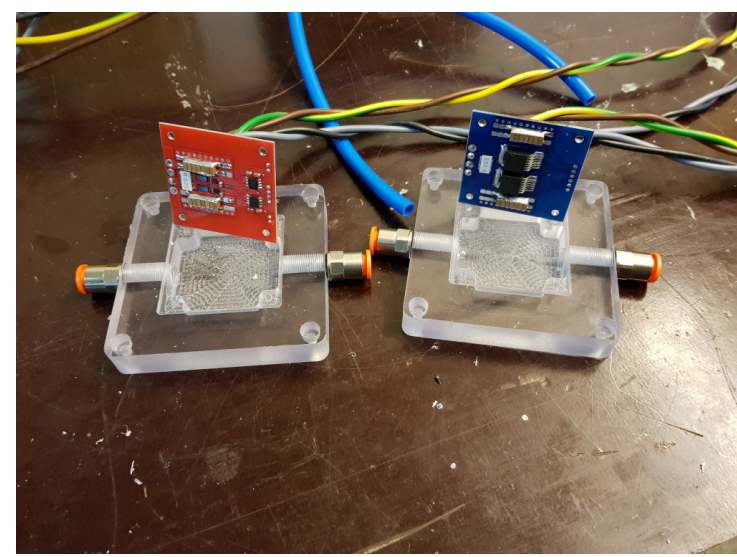

b)

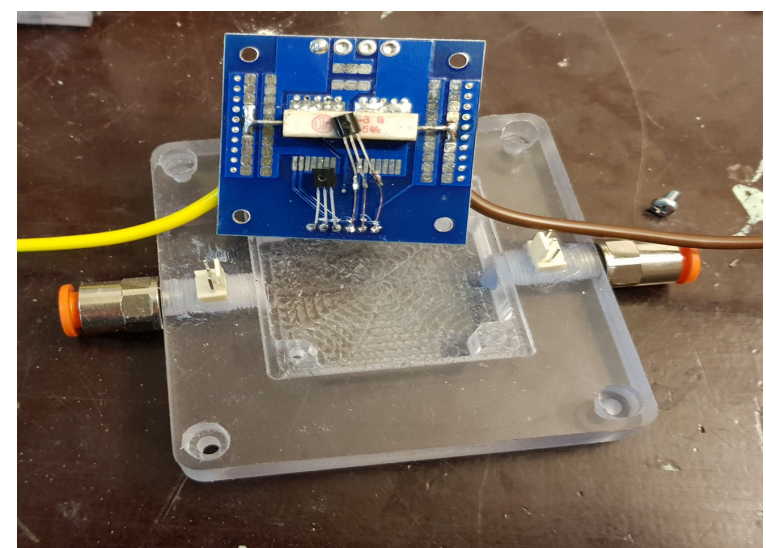

Fig. 6. Cases for direct liquid cooling of hybrid micro modules of power inverters with silicone oil (a) and location of temperature sensors on hybrid micro-module board (b)

Two temperature sensors (Fig. 5 and Fig. 6.b) were installed on the boards of the modules for measuring the temperature of the incoming and out flowing coolant streams. This allowed us to 
determine the temperature gradient of the cooling liquid flow in the case and the temperature of the transistors.

\section{Results of the research of developed hybrid micro modules of power inverters}

During the studies, we determined the influence of the switching frequency of power inverters of hybrid micro modules on the efficiency of inverters, when using direct liquid cooling with silicone oil. The voltage of the regulated power supply was $300 \mathrm{~V}$, and the frequency of the signal generator was changed from $100 \mathrm{kHz}$ to $300 \mathrm{kHz}$, and the temperature of the modules was maintained by the cooling system of about $60^{\circ} \mathrm{C}$.

Fig. 7.a shows that the output power decreases, if the switching frequency is increased in both one and the other power hybrid micro module. When the switching frequency is $100 \mathrm{kHz}$, the output power exceeds $3 \mathrm{~kW}$, when using a hybrid power micro module made on SiC MOSFETs C3M0065090J, while using a micro module made on eGaN transistors EPC2035, the output power value did not reach $2.5 \mathrm{~kW}$. Operating frequency increase leads to a significant decrease in the output power, when using a power micro module made on SiC MOSFETs C3M0065090J: the output power is $1 \mathrm{~kW}$, when the operating frequency is $200 \mathrm{kHz}$. When using a micro module made on eGaN transistors EPC2035, the output power drop is smaller with increasing the operating frequency. The liquid cooling is more efficient for this module, since the EPC2035 transistors are open-core transistors, and the heat removal is more efficiently performed from these transistors, and the power decrease is determined only by the electrical characteristics of the transistors EPC2035.

a)

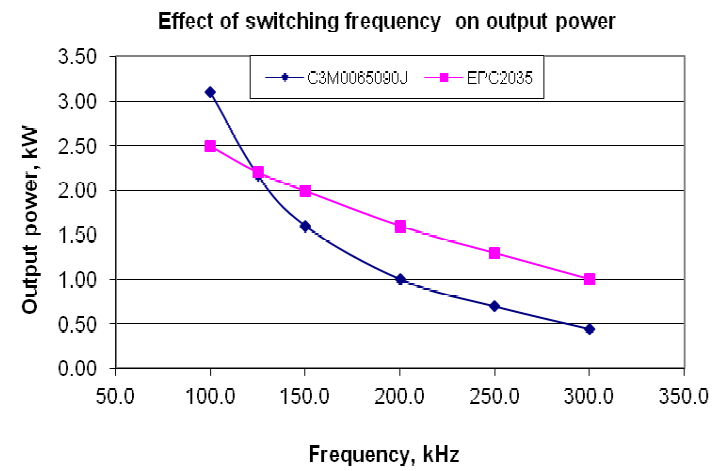

b)

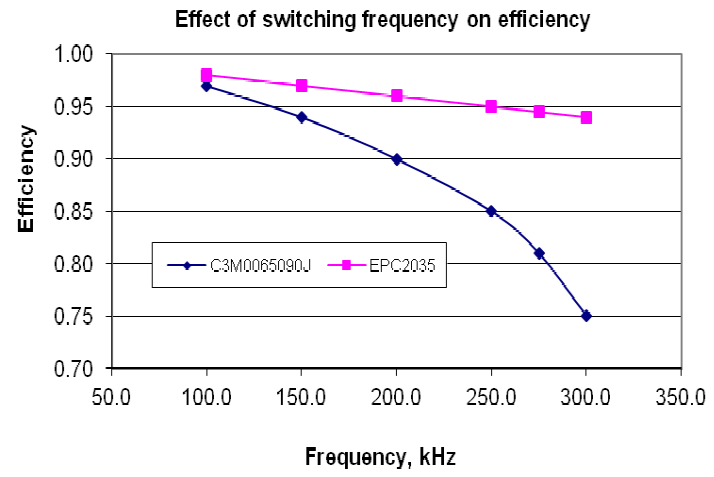

Fig. 7. Dependencies of output power (a) and efficiency (b) of power inverters of hybrid micro modules on frequency with direct liquid cooling

Figure 7.b shows the efficiency dependencies on the switching frequency of the power inverters of hybrid micro modules. It can be seen that the increase in frequency results in a significant decrease in the efficiency, when using the power inverters of the hybrid micro module made on SiC MOSFETs C3M0065090J. When the operating frequency is $100 \mathrm{kHz}$, the efficiency is about 0.97 , which means that the loss is 100 watts. When the operating frequency is $200 \mathrm{kHz}$, the efficiency reduction is 0.1 , which means that the output power loss is 300 watts. When using a micro module made on eGaN transistors EPC2035, the efficiency decreases to a less extent. It can be seen that the efficiency is 0.98 , if the operating frequency is $100 \mathrm{kHz}$ and the output power is $2.4 \mathrm{kw}$, that is, the loss is less than 50 W. The efficiency of the module exceeds 0.9 , even at $300 \mathrm{kHz}$, if you use eGaN transistors EPC2035.

The output power and efficiency values shown in Fig. 7 are average values of the input and output powers of the inverters obtained in the process of 10 experiments for each frequency value, and the maximum relative standard deviation of the measurement results did not exceed $2 \%$.

\section{Conclusions}

1. eGaN - transistors EPC2035 allow the creation of higher frequency, high-density hybrid micromodules of power inverters, as eGaN - transistors have microminiature dimensions.

2. MOSFETs C3M0065090J allow the creation of more powerful hybrid micro modules of power inverters with a switching frequency of less than $150 \mathrm{MHz}$. 
3. To create hybrid power-inverter modular modules it is necessary to use passive components with increased requirements to their parameters.

4. Direct liquid cooling provides higher efficiency of hybrid micro modules of power inverters on transistors EPC2035 than for modules on MOSFETs C3M0065090J, the EPC2035 transistors are open-core transistors.

\section{Acknowledgements}

This paper has been published within the research project "Smart Engineering, Transport and Energy Competence Centre" project number: 1.2.1.1/16/A/008.

\section{References}

[1] Musavi F., Cracium M. etc. An LLC resonant DC-DC converter for wide output voltage range battery charging applications. IEEE Trans. Power Electronics, vol. 28, 2013, pp. 5437-5445.

[2] Yang J. W., Do H. L. High-efficiency ZVS AC-DC LED driver using a self-driven synchronous rectifier. IEEE Trans. Circuits Syst., vol. 61, 2014, pp. 2505-2512.

[3] Lee S. W., Do H. L. Single-stage bridgeless AC-DC PFC converter using a lossless passive snubber and valley switching. IEEE Trans. Ind. Electron., vol. 63, 2016, pp. 6055-6063.

[4] Wintrich A., Nicolai U. etc. Application Manual Power Semiconductors. Ilmenau: SEMIKRON International, 2011. $466 \mathrm{p}$.

[5] Biela J., Schweizer M. and Waffler S. SiC versus Si - Evaluation of Potentials for Performance Improvement of Inverter and DC-DC Converter Systems by SiC Power Semiconductors. IEEE transactions on industrial electronics, vol. 58, 2011, pp. 2872-2882.

[6] Everts J., Dasz J., Van den Keybusx J. etc. GaN-Based Power Transistors for Future Power Electronic Converters. PIEEE Benelux Young Researchers Symposium (YRS2010). [online] [12.03.2018]. Available at: https://lirias.kuleuven.be/handle/123456789/268624

[7] Saums D. Vehicle Electrification Thermal Management Challenges and Solutions Overview, MEPTEC Thermal Management Workshop, San Jose CA USA, March 2011. [online] [18.03.2011]. Available at: www.dsa-thermal.com

[8] Hannemann R. Thermal control of electronics: perspectives and prospects. [online] [01.03.2011]. Available at:http://web.mit.edu/hmtl/www/papers/HANNEMANN.pdf

[9] Advanced Cooling for Power Electronics. [online] [03.07.2017]. Available at:https://www.electronics-cooling.com/2017/07/advanced-cooling-power-electronics/

[10]C3M0065090J. Silicon Carbide Power MOSFET. [online] [15.02.2012]. Available at: https://www.wolfspeed.com/media/downloads/145/C3M0065090J.pdf

[11]EPC2035 - Enhancement Mode Power Transistor. [online] [31.01.2013]. Available at: https://epc-co.com/epc/Portals/0/epc/documents/datasheets/EPC2035_datasheet.pdf

[12] Boukhanouf R., Haddad A. A CFD Analysis of an electronics cooling enclosure for application in telecommunication systems. Applied Thermal Engineering, Elsevier, vol. 30, 2010, pp. 24262434.

[13] Sukhvinder S. K. Advanced Cooling for Power Electronics. [online] [20.09.2016]. Available at: https://www.researchgate.net/publication/254026620_Advanced_Cooling_for_Power_Electronics 